\title{
A Uniform Approach to Modeling Risk Factor Relationships for Ischemic Lesion Prevalence and Extent: The Women's Health Initiative Magnetic Resonance Imaging Study
}

\author{
Janet A. Tooze ${ }^{a}$ Sarah A. Gaussoin $^{a}$ Susan M. Resnick \\ Nancy J. Fischbein ${ }^{d}$ Jennifer G. Robinson ${ }^{e}$ R. Nick Bryan ${ }^{f}$ Yang An $^{c}$ \\ Mark A. Espeland ${ }^{a}$ for the Women's Health Initiative Memory Study \\ ${ }^{a}$ Department of Biostatistical Sciences, Wake Forest University Health Sciences, Winston-Salem, N.C., baboratory \\ of Personality and Cognition/03, Gerontology Research Center, NIA, NIH, and ' MedStar Research Institute, \\ Baltimore, Md., dDepartment of Radiology, Stanford University, Stanford, Calif., e Department of Epidemiology and \\ Department of Medicine, Lipid Research Clinic, University of lowa, lowa City, lowa, and fDepartment of Radiology, \\ University of Pennsylvania Health System, Philadelphia, Pa., USA
}

\section{Key Words}

Statistical methods • Brain magnetic resonance imaging • Cognition - Women's health

\begin{abstract}
Background: Both the prevalence and extent of brain magnetic resonance imaging (MRI) abnormalities are related to risk factors for dementia. Typically these associations have been explored separately, but an integrated modeling approach would allow the separate relationships to be consistently described and contrasted. Methods: Region-specific measures of ischemic lesion volumes were obtained from standardized brain MRI from 1,403 women enrolled in the Women's Health Initiative hormone therapy trials. Mixed-effects mixed-distribution models were fitted to explore jointly the relationships that the region-specific prevalence of ischemic lesions and region-specific ischemic lesion volumes had with risk factors and scores from tests of cognitive
\end{abstract}

function. Results: Women with greater probabilities (prevalence) of having ischemic lesions in brain regions also tended to have larger volumes (extent) of ischemic lesions within the affected regions $(p<0.001)$. Across the 5 regions included in analyses (frontal, limbic, occipital, parietal and temporal), prevalence and extent varied $(p<0.001)$. Each was increased among women who were older, had hypertension or who had previously been classified as cognitively impaired $(p<0.01)$. Additionally, extent was significantly increased among women with a history of smoking $(p=0.02)$. Cognitive function tests were more strongly related to the extent than prevalence of ischemic lesions and relationships varied among cognitive domains $(p<0.001)$. Conclusions: Mixed-effects mixed-distribution models provide a coherent basis for examining relationships involving the prevalence and extent of ischemic brain lesions. Across the cohort and regions we examined, relationships with risk factors and cognitive function appeared to be stronger for extent than for prevalence.
Copyright $\odot 2009$ S. Karger AG, Basel

\section{KARGER}

(ㄷ) 2009 S. Karger AG, Basel

Fax +41613061234

E-Mail karger@karger.ch

www.karger.com www.karger.com/ned
Janet Tooze, $\mathrm{PhD}$, Associate Professor

Department of Biostatistical Sciences, Division of Public Health Sciences

Wake Forest University Health Sciences, Medical Center Blvd.

Winston-Salem, NC 27157 (USA)

Tel. +1 336716 3833, Fax +1 336716 6427, E-Mail jtooze@wfubmc.edu 


\section{Introduction}

Both the prevalence $[1-5]$ and volume $[3,5-7]$ of abnormalities (e.g. infarcts, areas of white-matter hyperintensity) detected by brain magnetic resonance imaging (MRI) are important measures for neuroepidemiological research. While such measures are intercorrelated, the relationships that they have with risk factors may vary [8] and are often separately explored. A more integrated and potentially more informative approach is to examine these jointly within a general model. This allows investigators to distinguish individuals with numerous diffuse small ischemic lesions from those with a small number of large ischemic lesions and to explore whether there are different predictors for prevalence and extent. Such a model would need to address the intra- and intercorrelation of these measures across brain regions.

Recent progress in statistical research has developed a class of mixed-effect mixed-distribution (MEMD) models, and algorithms for fitting models, suitable for this approach $[9,10]$. This paper is designed to introduce these methods to radiological research. The models we describe allow simultaneous fitting of separate risk factor prediction models to the region-specific prevalence and extent of ischemic lesion volumes in a repeated measures framework. Intraindividual correlations among regions of the brain and correlations between individuals' overall prevalence rates and ischemic lesion volumes are addressed. In this manuscript, we describe these tools and apply them to data from standardized MRI readings from a large cohort of older women to assess their relationships to dementia risk factors and cognitive function. Because our primary goal is to describe this methodology, results are provided as examples of potential applications, and extensive analyses are not reported.

\section{Materials and Methods}

The Women's Health Initiative Memory Study Magnetic Resonance Imaging (WHIMS-MRI) was an ancillary study to the Women's Health Initiative (WHI) trials of hormone therapy [11], two large, randomized, double-blind, placebo-controlled, clinical trials of postmenopausal hormone therapy: $0.625 \mathrm{mg} /$ day conjugated equine estrogen alone or in combination with $2.5 \mathrm{mg} /$ day of continuous medroxyprogesterone acetate. The WHIMS-MRI was undertaken to contrast neuroradiological outcomes among women who had been assigned to active versus placebo therapy during the WHI trials [12-14]. Exclusion criteria were the presence of pacemakers, defibrillators, neurostimulators, prohibited medical implants and foreign bodies (e.g. bullets, shrapnel, metal slivers) that would pose a hazard during the MRI procedure. Oth- er exclusion criteria were shortness of breath and/or inability to lie flat, as well as conditions that can be exacerbated by stress (e.g. anxiety panic disorders, claustrophobia, uncontrolled high blood pressure or seizure disorders) severe enough to preclude an MRI. At 14 US academic centers, 1,424 women underwent a brain MRI, and 1,403 had scans containing usable data. Written informed consent was obtained from all participants. The NIH and institutional review boards approved the protocol and consent forms.

\section{Brain Magnetic Resonance Imaging}

Brain MRI scans were conducted at multiple sites and analyzed centrally using a standardized protocol $[13,14]$ that represents the evolution in image processing from manual human observer to automatic quantitative computerized digital image analytical techniques that are not only correlated with human observers and the semiquantitative scoring systems, but are also very reproducible and offer a greater dynamic range [15-17].

MRI scanning pulse sequences were performed in the following order:

- series 1 = 3-plane gradient echo localizer for positioning;

- series 2 = sagittal $\mathrm{T}_{1}$-weighted imaging to demonstrate anatomical location of the $\mathrm{AC} / \mathrm{PC}$ for slice angle and slice position;

- series 3 = oblique axial spin density/ $\mathrm{T}_{2}$-weighted imaging from the vertex to skull base parallel to the AC/PC plane;

- series 4 = oblique axial FLAIR $\mathrm{T}_{2}$-weighted imaging, matching slice positions in series 3 ;

- series 5 = oblique axial 3 -dimensional SPGR $\mathrm{T}_{1}$-weighted imaging from the vertex to skull base parallel to the AC/PC plane.

A trained technologist reviewed all scans for technical problems, protocol compliance and participant motion. If a series needed repeating, this was done before the participant was removed from the scanner. Imaging data were then transmitted using a DICOM image transfer mechanism for central reading at the Department of Radiology, University of Pennsylvania.

Gray and white matter was classified as either normal or 'ischemic' with areas of ischemia corresponding to what is generally referred to as 'small-vessel ischemic disease' (ischemic white-matter disease and lacunar infarctions). Ischemic white-matter disease represents a nonnecrotic, ischemic effect on myelin that is secondary to the effects of aging, hypertension and other smallvessel pathological processes of the brain $[18,19]$. Separate volumes (total and ischemic lesion) were provided for 92 anatomical regions of interest in the cerebrum. Examples in this paper are based on 5 regions (frontal lobe, limbic region, occipital lobe, parietal lobe and temporal lobe), which were chosen to provide ranges of size and prevalence. Total volumes for each of these regions were calculated by summing across the smaller subregions.

\section{Risk Factors and Measures of Cognitive Function}

The dementia risk factors included as examples in this report were collected by standardized procedures of the WHI at enrollment [11]. These include age and smoking history. Hypertension was based on current treatment or measured blood pressure exceeding 140/90 mm Hg. Self-reported vascular disease included myocardial infarction, stroke, angina, percutaneous transluminal coronary angioplasty, coronary artery bypass grafting or stroke. WHI treatment assignment (hormone therapy versus placebo) was also included in analyses. 
Global cognitive function had been measured annually in these women with the Modified Mini Mental State Examination $[20,21]$. It consists of 15 items that sum to $0-100$; higher scores reflect better cognitive functioning. Test items measure temporal and spatial orientation, immediate and delayed recall, executive function, naming, verbal fluency, abstract reasoning, praxis, writing and visuoconstructional abilities. The average (and SD) time that the most recent Modified Mini Mental State Examination test preceded the MRI was by $0.42(0.70)$ years. Approximately $70 \%$ of the participants $(n=1,079)$ had also been enrolled in the WHI Study of Cognitive Aging [22], which administered an annual cognitive battery to assess a broad range of domain-specific cognitive functions. Included in the battery were the Primary Mental Abilities vocabulary test [23] to measure verbal knowledge, letter and semantic fluency tests $[24,25]$ to measure phonemic and category fluency, the Benton Visual Retention Test [26] to measure short-term figural memory and visuoconstruction, the California Verbal Learning Test [27] to measure verbal learning and memory, the Digit Span Test [28] to measure attention and working memory, the Card Rotation Test [29] to measure spatial rotational ability, and a finger tapping test [30] to measure fine motor speed. The average (and SD) time that the most recent battery preceded the MRI was by $0.75(0.84)$ years.

\section{Statistical Methods}

\section{Statistical Model}

The underlying MEMD model, as developed by Tooze et al. [9, 10], consists of linked mixed model regression equations to parameterize relationships with ischemic lesion prevalence and extent of ischemic lesions. It is considered a 2-part model, because prevalence and extent are modeled in 2 regression equations, with covariates that are allowed to vary for each part of the model. It is called a 'mixed model' because it includes a mix of fixed effects (the effects of specific variables of interest) and a person-specific random effect in each of the 2 parts of the model. The separate personspecific random effect terms are included to address intrasubject correlations of prevalence among regions and ischemic lesion volumes among regions. However, even though prevalence and extent are modeled in separate regression equations, they are not independent because a shared parameter is used to express the correlation between the intraregional probability of having a lesion (i.e. prevalence) and the intraregional lesion volume (i.e. extent).

The first part of the model estimates the probability (prevalence) of having a lesion within a region using logistic regression with a person-specific random effect (mixed model). The random effect is a latent variable that captures an individual's tendency to have lesions, after adjusting for the fixed effects of covariates. It is necessary to include this random effect in the model due to the within-person correlation that arises from modeling multiple regions simultaneously. The model for part I is:

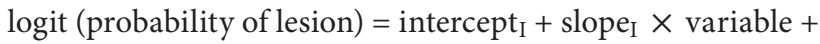
person-specific effect ${ }_{I}$

where, for probability $\mathrm{p}, \operatorname{logit}(\mathrm{p})=\log (\mathrm{p} / 1-\mathrm{p})$. The subscript I indicates the association of the parameters with part I. One predictor variable is shown in the equation, but the model allows for multiple predictor variables (or no variables). These may represent region-specific characteristics (e.g. total regional volume) or person-specific characteristics (e.g. dementia risk factors, cognitive test scores), as we demonstrate.

Modeling Ischemic Lesion Prevalence
The second part of the model predicts the ischemic lesion volume (extent) among those who have lesions. Similar to part I, part II may incorporate predictor variables of interest, which may or may not be the same variables used in part I. The model for part II is:

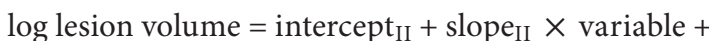
person-specific effect ${ }_{I I}+$ within-person variability $y_{I I}$

The subscript II indicates the association of these parameters with part II. As in part I, the model is a mixed one, modeling both fixed effects of covariates, and a random person-specific effect. The random effect models the individual's general extent of lesion volume, which is correlated across multiple brain regions within an individual. The intercept terms of parts I and II represent person-specific random effects, which are assumed to follow a bivariate normal distribution and are used to link the two underlying expressions. The joint model is fitted using the maximum likelihood method with a SAS software (version 9.1, SAS Institute, Cary, N.C., USA) macro (which may be obtained from the corresponding author). Correlation of prevalence and extent may be determined by means of a likelihood ratio test comparing the joint model to a model that fits prevalence and extent separately; this test is implemented in the macro.

\section{Modeling of Abnormal Volume in WHIMS-MRI}

The prevalence and extent of ischemic lesions were analyzed using the 2-part MEMD model described above, including markers for the 5 regions of interest in which parameters for variables were constrained to sum to zero. To demonstrate the use of region-specific predictors, total regional volumes were included in models. Two sets of subject-specific predictors were considered. The relationships that ischemic lesion prevalence and extent had with dementia risk factors (age, smoking status, hypertension, prior cardiovascular disease and assignment to hormone therapy) were examined in separate models with adjustment for regionspecific volumes. The relationships with cognitive test scores were examined in a similar manner. The interregional consistency of these relationships was assessed using interaction terms. Ischemic lesion volumes were highly right-skewed; Box-Cox transformations supported the use of lognormal models for extent. The parameters of the lognormal model may be interpreted as an nfold change in the median lesion volume.

\section{Results}

Table 1 characterizes the 1,403 women, whose age averaged 78.5 years and ranged from 72.0 to 88.6 years at the time of their MRI.

Table 2 describes the distribution of the volumes of the brain regions included in our analyses, the percentage of each region that contained ischemic lesions, and, for regions containing ischemic lesions, the mean total volume of these lesions. The frontal, temporal and parietal regions were the largest, had the greatest prevalence of ischemic lesions and, in regions in which lesions occurred, 
Table 1. Distribution of risk factors for ischemic lesions

\begin{tabular}{|c|c|}
\hline Dementia risk factor & Distribution \\
\hline \multicolumn{2}{|l|}{ Age at time of MRI, years } \\
\hline Mean & 78.5 \\
\hline Range & $72.0-88.6$ \\
\hline \multicolumn{2}{|l|}{ Smoking status at WHI enrollment } \\
\hline Never & $806(57.9)$ \\
\hline Former/current & $585(42.1)$ \\
\hline \multicolumn{2}{|l|}{ Hypertension status at WHI enrollment } \\
\hline No & $688(49.0)$ \\
\hline Yes & $815(51.0)$ \\
\hline \multicolumn{2}{|c|}{ Prior cardiovascular disease at WHI enrollment } \\
\hline No & $1,313(93.6)$ \\
\hline History of cardiovascular disease & $90(6.4)$ \\
\hline \multicolumn{2}{|l|}{ WHI treatment assignment } \\
\hline Active CEE & $257(18.8)$ \\
\hline Placebo CEE & $263(18.3)$ \\
\hline Active CEE and MPA & $436(311)$ \\
\hline Placebo CEE and placebo MPA & $447(31.9)$ \\
\hline \multicolumn{2}{|c|}{$\begin{array}{l}\text { Figures in parentheses indicate percentages. Hypertension de- } \\
\text { fined as blood pressure measured to exceed } 140 / 90 \mathrm{~mm} \mathrm{Hg} \text { or use } \\
\text { of current antihypertensive treatment. Cerebrovascular disease } \\
\text { defined as myocardial infarction, stroke, angina, percutaneous } \\
\text { transluminal coronary angioplasty, coronary artery bypass graft- } \\
\text { ing or stroke. CEE = Conjugated equine estrogen; MPA = me- } \\
\text { droxyprogesterone acetate. }\end{array}$} \\
\hline
\end{tabular}

had the greatest mean total volumes of lesions. Differences in the prevalence and extent of ischemic lesions among regions remain after adjustment for region-specific total volumes (both $\mathrm{p}<0.001$ ), as demonstrated in table 3 . The logistic regression parameters for prevalence portray the relative ordering of regions compared to the overall mean and can be transformed to odds ratios. After adjustment for differences in volume, frontal lobes had an $\mathrm{e}^{2.032}=7.63$ (95\% confidence interval, CI: 0.99_ 58.82) times higher odds of prevalent ischemic lesions than the average of other regions. The lognormal regression parameters express differences in ischemic lesion volumes: after adjustment for total regional volumes, the median volumes of ischemic lesions in the frontal lobe were 0.22 (95\% CI: 0.12-0.39) times as large as the median across all regions. There was a significant withinperson correlation between the prevalence and extent of ischemic lesions: the greater the number of affected regions, the larger the ischemic lesion volumes tended to be within affected regions $(\mathrm{p}<0.0001)$. Overall, prevalence and extent of lesions tended to be greater among larger
Table 2. Mean regional volumes, prevalence of ischemic lesions and ischemic lesion volumes $\pm \mathrm{SD}$

\begin{tabular}{lcll}
\hline Region & $\begin{array}{l}\text { Total regional } \\
\text { volume, } \mathrm{cm}^{3}\end{array}$ & $\begin{array}{l}\text { Prevalence of } \\
\text { regions with } \\
\text { ischemic lesion } \\
\text { volumes, \% }\end{array}$ & $\begin{array}{l}\text { Ischemic } \\
\text { lesion } \\
\text { volume, } \mathrm{cm}^{3}\end{array}$ \\
\hline Frontal lobe & $283.88 \pm 28.92$ & 98.1 & $3.43 \pm 5.07$ \\
Limbic region & $31.63 \pm 4.48$ & 17.7 & $0.26 \pm 0.32$ \\
Occipital lobe & $102.14 \pm 12.72$ & 74.5 & $0.68 \pm 0.84$ \\
Parietal lobe & $152.85 \pm 15.69$ & 85.1 & $2.32 \pm 3.62$ \\
Temporal lobe & $184.18 \pm 18.72$ & 87.4 & $1.85 \pm 2.17$ \\
\hline
\end{tabular}

Ischemic lesion volume of regions with prevalent ischemic lesions.

regions; interaction terms could be added to the models to examine associations with region-specific volumes within regions.

Age and hypertension were each significantly related to the prevalence of ischemic lesions across regions (both $\mathrm{p}<0.001$ ), as shown in table 4 . Separately, these estimates indicate that within regions, the odds of prevalent ischemic lesions increased for each year of additional age by a factor of $\mathrm{e}^{0.090}=1.09$ (95\% CI: $\left.1.06-1.13\right)$ and among women with hypertension by 1.50 (95\% CI: 1.18-1.91). The volumes of lesions were also significantly related to age and hypertension: each year of age was associated with an increase in the median volume by a factor of $\mathrm{e}^{0.054}=1.06$ (95\% CI: 1.04-1.07) and hypertension was associated with an increase in the median volume by a factor of 1.27 (95\% CI: 1.13-1.42). Smoking was significantly associated with increased lesion volume $(\mathrm{p}=0.02)$, but not with increased prevalence $(\mathrm{p}=0.21)$. Prior onstudy classification of cognitive impairment (either mild cognitive impairment or probable dementia) was associated with increased odds of prevalent lesions by a factor of 2.39 (95\% CI: 1.24-4.61) and an increased median lesion volume by a factor of 1.49 (95\% CI: 1.11-1.99), both $\mathrm{p}<0.01$. Neither history of cardiovascular disease nor on-trial assignment to hormone therapy were associated with the prevalence or extent of ischemic lesions (all p > $0.10)$.

Relationships that scores from tests of cognitive function had with prevalence all were in the expected direction (table 5) but reached statistical significance only for category fluency $(p=0.05)$. Overall, the relationships these test scores had with the extent of region-specific 
Table 3. Relationships that prevalence and extent have with region-specific volumes: fitted regression coefficients, standard errors (in parentheses) and $\mathrm{p}$ values with adjustment for regional volumes and correlations between prevalence and extent

\begin{tabular}{|c|c|c|c|c|}
\hline \multirow[t]{2}{*}{ Predictor } & \multicolumn{2}{|c|}{$\begin{array}{l}\text { Logistic regression } \\
\text { parameter with prevalence }\end{array}$} & \multicolumn{2}{|c|}{$\begin{array}{l}\text { lognormal regression } \\
\text { parameter with extent }\end{array}$} \\
\hline & $\beta$ & $\mathrm{p}$ value & $\beta$ & $\mathrm{p}$ value \\
\hline Volume of region & $0.010(0.003)$ & $0.005^{1}$ & $0.006(0.001)$ & $<0.001^{1}$ \\
\hline \multicolumn{5}{|l|}{ Region } \\
\hline Frontal lobe & $2.032(1.042)$ & & $-1.514(0.296)$ & \\
\hline Limbic region & $-3.106(0.417)$ & & $-1.194(0.110)$ & \\
\hline Occipital lobe & $0.103(0.182)$ & $<0.001^{2}$ & $-0.069(0.047)$ & $<0.001^{2}$ \\
\hline Parietal lobe & $0.546(0.088)$ & & $0.482(0.023)$ & \\
\hline Temporal lobe & $0.504(0.147)$ & & $0.325(0.036)$ & \\
\hline
\end{tabular}

${ }^{1}$ Overall relationship with regional volume.

${ }^{2}$ Consistency of relationships with regional volumes among regions.

Table 4. Relationships that prevalence and extent have with risk factors for ischemic lesions: fitted regression coefficients, standard errors (in parenhteses) and $p$ values with adjustment for differences in volumes and correlations among regions

\begin{tabular}{|c|c|c|c|c|}
\hline \multirow[t]{2}{*}{ Risk factor } & \multicolumn{2}{|c|}{$\begin{array}{l}\text { Logistic regression } \\
\text { parameter with prevalence }\end{array}$} & \multicolumn{2}{|c|}{$\begin{array}{l}\text { lognormal regression } \\
\text { parameter with extent }\end{array}$} \\
\hline & $\beta$ & $\mathrm{p}$ value & $\beta$ & $\mathrm{p}$ value \\
\hline Age & $0.090(0.017)$ & $<0.001$ & $0.054(0.008)$ & $<0.001$ \\
\hline Ever smoked & $0.156(0.124)$ & 0.21 & $0.140(0.058)$ & 0.02 \\
\hline Hypertension & $0.408(0.123)$ & $<0.001$ & $0.236(0.057)$ & $<0.001$ \\
\hline Prior cardiovascular disease & $0.270(0.252)$ & 0.28 & $0.190(0.117)$ & 0.11 \\
\hline Assignment to active hormone therapy & $0.132(0.122)$ & 0.28 & $0.054(0.057)$ & 0.35 \\
\hline Mild cognitive impairment or probable dementia & $0.873(0.334)$ & 0.009 & $0.396(0.149)$ & 0.008 \\
\hline
\end{tabular}

ischemic lesion volumes tended to be stronger than those for prevalence, with significance achieved for global cognitive function and the domains of verbal knowledge, verbal fluency, memory and spatial ability.

Table 5 portrays relationships between domain-specific cognitive function and ischemic lesions across all 5 brain regions. Interaction terms can be included in the MEMD models to examine the consistency of relationships among regions and to explore whether there may be evidence of region-specific relationships with individual domains. For example, the relationship between the extent of ischemic lesion volumes and performance on the card rotation varied significantly by region (test for interaction $\mathrm{p}<0.001)$. Table 6 describes this interaction, list- ing the degree (expressed as percent) by which the median volume of ischemic lesions increases for each 10 points worse score on the Card Rotation Test. The limbic region was chosen as a reference because the association between the extent of ischemic lesion volumes and performance in the Card Rotation Test appeared to be weakest for this region. The strongest associations were for the frontal, parietal and temporal lobes for which the 95\% confidence intervals excluded 0 . As an example of how the results can be interpreted, a score of 10 points worse on the Card Rotation Test was associated with approximately a $9 \%$ greater increase in ischemic lesion volumes in the frontal and parietal lobes than in the limbic region. 
Table 5. Relationships that prevalence and extent have with cognitive test scores: fitted regression coefficients, standard errors (in parentheses) and $\mathrm{p}$ values with adjustment for differences in regional volumes and correlations among regions

\begin{tabular}{|c|c|c|c|c|}
\hline \multirow[t]{2}{*}{ Cognitive test score } & \multicolumn{2}{|c|}{$\begin{array}{l}\text { Logistic regression } \\
\text { parameter with prevalence }\end{array}$} & \multicolumn{2}{|c|}{$\begin{array}{l}\text { lognormal regression } \\
\text { parameter with extent }\end{array}$} \\
\hline & $\beta$ & $\mathrm{p}$ value & $\beta$ & $\mathrm{p}$ value \\
\hline \multicolumn{5}{|l|}{ Global cognitive function } \\
\hline $3 \mathrm{MS}$ & $-0.029(0.016)$ & 0.08 & $-0.026(0.007)$ & $<0.001$ \\
\hline \multicolumn{5}{|l|}{ Verbal knowledge } \\
\hline PMA vocabulary & $-0.010(0.008)$ & 0.19 & $-0.009(0.004)$ & 0.01 \\
\hline \multicolumn{5}{|l|}{ Verbal fluency } \\
\hline Letter fluency & $-0.004(0.005)$ & 0.47 & $-0.000(0.002)$ & 0.94 \\
\hline Category fluency & $-0.021(0.011)$ & 0.05 & $-0.015(0.005)$ & 0.002 \\
\hline \multicolumn{5}{|l|}{ Memory } \\
\hline BVRT errors $^{1}$ & $0.016(0.019)$ & 0.40 & $0.026(0.009)$ & 0.002 \\
\hline CVLT total list A & $-0.011(0.010)$ & 0.27 & $-0.015(0.005)$ & 0.001 \\
\hline CVLT short delay free & $-0.037(0.021)$ & 0.08 & $-0.041(0.010)$ & $<0.001$ \\
\hline CVLT long delay free & $-0.017(0.022)$ & 0.42 & $-0.032(0.010)$ & 0.001 \\
\hline \multicolumn{5}{|l|}{ Attention and working memory } \\
\hline Digits forward & $0.032(0.032)$ & 0.32 & $0.024(0.015)$ & 0.11 \\
\hline Digits backward & $0.022(0.019)$ & 0.24 & $0.006(0.009)$ & 0.51 \\
\hline \multicolumn{5}{|l|}{ Spatial ability } \\
\hline Card Rotation Test & $-0.003(0.002)$ & 0.18 & $-0.003(0.001)$ & 0.001 \\
\hline \multicolumn{5}{|l|}{ Fine motor speed } \\
\hline Finger tapping dominant hand & $-0.012(0.010)$ & 0.25 & $-0.004(0.005)$ & 0.36 \\
\hline Finger tapping nondominant hand & $-0.020(0.012)$ & 0.09 & $-0.008(0.006)$ & 0.17 \\
\hline
\end{tabular}

Table 6. Relative region-specific increases in median ischemic lesion volume associated with each 10 -point lower score on the card rotation test

\begin{tabular}{lll}
\hline Region & $\begin{array}{l}\text { Percent increase in } \\
\text { median ischemic lesion } \\
\text { volume relative to } \\
\text { limbic region }\end{array}$ & \\
& $95 \% \mathrm{CI}$ \\
\hline Frontal lobe & 8.8 & $7.1-10.0$ \\
Occipital lobe & 1.0 & $2.6-4.5$ \\
Parietal lobe & 9.0 & $7.1-10.9$ \\
Temporal lobe & 6.5 & $4.8-8.2$ \\
Limbic region (reference) & 1.00 & - \\
\hline
\end{tabular}

\section{Discussion}

The MEMD-based approach that we describe provides a uniform approach to modeling the relationships that individual's characteristics (e.g. risk factors, measures of cognitive function) have with region-specific prevalence and extent of MRI-detected abnormalities, predominantly white-matter small-vessel ischemic lesions. This approach controls for intrasubject correlations and for any correlation between the prevalence and extent of imaging abnormalities among regions, using random effects terms. If not addressed in models, these correlations would be expected to confound results from separate analyses of relationships with prevalence and extent. MEMD models accommodate region-specific covariates (e.g. total regional brain volumes) in addition to individual-specific characteristics: this allows covariate adjustment for comparisons among regions. Interaction 
terms can be included to assess the consistency of relationships among brain regions, as we have demonstrated. Documentation and software for fitting models are available from the first author.

We have included as examples analyses that reveal several features of ischemic lesion volumes that support the use of MEMD models. We found that the prevalence and extent of ischemic lesions among regions were strongly correlated. In the WHIMS-MRI cohort, the prevalence and volume of ischemic lesions varied among the 5 regions we considered, and regions that tended to be larger were more likely to have greater prevalence and volume of lesions. While within-region relationships between total volume and ischemic lesions are of interest, comparisons among regions benefit from multivariate approaches such as we describe, and from the use of region-specific covariates. The volumes of ischemic lesions were right-skewed, which warranted the use of a lognormal distribution governing differences among regions between individuals. Overall, we found that ischemic lesion extent tended to have stronger associations with dementia risk factors and measures of cognition than ischemic lesion prevalence, suggesting that, on average, volume may be a stronger measure of disease burden.

The limited analyses that we present as examples are of interest, but require further investigation. Age, hypertension and prior classification of cognitive impairment were strongly related to both the prevalence and extent of ischemic lesions, which is consistent with prior reports [2, $3,31]$. We also found that history of smoking was associated with greater extent [32]. Consistent with an earlier report, assignment to hormone therapy was not significantly associated with ischemic lesions [13]. Of the cognitive domains we examined, the strongest and most sig- nificant relationships linked the extent of ischemic lesion volumes with measures of global cognitive function, verbal knowledge, verbal category fluency, memory and spatial ability. As we have demonstrated, these may vary by brain region. More focused analyses that examine smaller and greater numbers of regions will be important for adding clarity to these relationships. By conducting these analyses in a multivariate fashion, we are able to compare their relative strengths among regions.

\section{Conclusion}

Two-part MEMD models provide a flexible and coherent approach towards modeling data on ischemic lesions detected by MRI scanning and should be considered as a general strategy for analyzing these data.

\section{Acknowledgments}

The WHI Memory Study was initially funded by Wyeth Pharmaceuticals Inc., St. Davids, Pa., USA, with sustaining support from the National Heart, Lung and Blood Institute, which also funded the WHI Magnetic Resonance Imaging Study. The WHI is funded by the National Heart, Lung and Blood Institute of the National Institutes of Health, US Department of Health and Human Services. Wyeth Pharmaceuticals provided the study drug and the placebo to the WHI trial. The WHI Study of Cognitive Aging was supported by the Department of Health and Human Services and the National Institute on Aging, N01-AG-9-2115, National Institutes of Health, Bethesda, Md., USA. This research was supported in part by the Intramural Research Program of the National Institutes of Health, National Institute on Aging; a portion of that support was through an R\&D contract with Medstar Research Institute.

\section{References}

1 Bryan RN, Cai J, Burke G, Hutchinson RG, Liao D, Toole JF, Dagher AP, Cooper L: Prevalence and anatomic characteristics of infarct-like lesions on MR images of middleaged adults: the Atherosclerosis Risk in Communities Study. Am J Neuroradiol 1999; 20:1273-1280.

-2 Longstreth WT, Dulberg C, Manolio TA, Lewis MR, Beauchamp NJ Jr, O'Leary D, Carr J, Furberg CD: Incidence, manifestations, and predictors of brain infarcts defined by serial cranial magnetic resonance imaging in the elderly. Stroke 2002;33:23762382 .

Modeling Ischemic Lesion Prevalence
- 3 Vermeer SE, Prins ND, den Heijer T, Hofman A, Koudstall PJ, Breteler MMB: Silent brain infarcts and the risk of dementia and cognitive decline. N Engl J Med 2003;348: 1215-1222.

4 Vermeer SE, Hollande M, van Dijk EJ, Hofman A, Koudstaal PJ, Breteler MMB: Silent brain infarcts and white matter lesions increase stroke risk in the general population. Stroke 2003;34:1126-1129.

$\checkmark 5$ De Carli C, Massaro J, Harvey D, Hald J, Tullberg M, Au R, Beiser A, D’Agostino R, Wolf PA: Measures of brain morphology and infarction in the Framingham Heart Study: establishing what is normal. Neurobiol Aging 2005;26:491-510.
6 Schmidt R, Scheltens P, Erkinjuntti T, Pantoni L, Markus HS, Wallin A, Barkhof F, Fazekas F: White matter lesion progression: a surrogate endpoint for trials in cerebral small-vessel disease. Neurology 2004;63: 139-144.

7 van der Flier WM, van der Vlies AE, Weverling-Rijnsburger AWE, de Boer NL, Admiraal-Behloul F, Bollen EMEM, Westendorp RGJ, van Buchern MA, Middelkoop HAM: MRI measures and progression of cognitive decline in nondemented elderly attending a memory clinic. Int J Geriatr Psychiatry 2005; 20:1060-1066. 
>8 Bisschops RHC, Klijn KJM, Kappelle LJ, van Huffelen AC, van der Grond J: Prevalence and volume of internal border zone lesions in patients with impaired cerebral carbon dioxide vasomotor reactivity. Arch Neurol 2003; 60:1233-1236.

-9 Tooze JA, Grunwald GK, Rones RH: Analysis of repeated measures data with clumping at zero. Statist Meth Med Res 2002;11:341355.

-10 Tooze JA, Midthune D, Dodd KW, Freedman LS, Krebs-Smith SM, Subar AF, Guenther PM, Carroll RJ, Kipnis V: A new statistical method for estimating the usual intake of episodically consumed foods with application to their distribution. J Am Diet Assoc 2006;106:1575-1587.

-11 The Women's Health Initiative Study Group: Design of the Women's Health Initiative clinical trial and observational study. Control Clin Trials 1998;19:61-109.

- 12 Jaramillo SA, Felton D, Andrews L, Desiderio L, Hallarn RK, Jackson SD, Coker LH, Robinson JG, Ockene JK, Espeland MA: Enrollment in a brain magnetic resonance study: results from the Women's Health Initiative Memory Study Magnetic Resonance Imaging Study (WHIMS-MRI). Acad Radiol 2007; 14:603-612.

-13 Coker LH, Hogan PE, Bryan NR, Kuller LH, Margolis KL, Bettermann K, Wallace RB, Lao Z, Freeman R, Stefanick ML, Shumaker SA: Postmenopausal hormone therapy and subclinical cerebrovascular disease: The WHIMS-MRI Study. Neurology 2009;72: 125-134.

14 Resnick SR, Espeland MA, Jaramillo SA, Hirsch C, Stefanick ML, Murray AM, Ockene J, Davatzikos C: Postmenopausal hormone therapy and regional brain volumes: The WHIMS-MRI Study. Neurology 2009; 72:135-142.
15 Anbeek P, Vincken KL, van Osch MJ, Bisschops RH, van der Grond J: Automatic segmentation of different-sized white matter lesions by voxel probability estimation. Med Image Anal 2004;8:205-215.

16 Yoshita M, Fletcher E, Harvey D, Ortega BS Martinez O, Mungas DM, Reed BR, De Carli CS: Extent and distribution of white matter hyperintensities in normal aging, MCI, and AD. Neurology 2006;67:2192-2198.

17 Lao Z, Shen D, Liu D, Jawad AF, Melhem ER, Launder LJ, Bryan RN, Davatzikos C: Computer-assisted segmentation of white matter lesions in 3D MR images using support vector machine. Acad Radiol 2008;15:300-313.

18 Pantoni L, Garcia JH: Pathogenesis of leukoaraiosis: a review. Stroke 1997;28:652-659.

19 Moody DM, Bell MA, Challa VR: Features of the cerebral vascular pattern that predict vulnerability to perfusion or oxygenation deficiency: an anatomic study. Am J Neuroradiol 1990;11:431-439.

20 Teng EL, Chui HC: The Modified MiniMental State (3MS) examination. J Clin Psychiatry 1987;48:314-318.

21 Shumaker SA, Reboussin BA, Espeland MA, Rapp SR, McBee WL, Dailey M, Bowen D, Terrell T, Jones BN: The Women's Health Initiative Memory Study: a trial of the effect of estrogen therapy in preventing and slowing the progression of dementia. Control Clin Trials 1998;19:604-621.

22 Resnick SM, Coker LH, Maki PM, Rapp SR, Espeland MA, Shumaker SA: The Women's Health Initiative Study of Cognitive Aging (WHISCA): a randomized clinical trial of the effects of hormone therapy on age-associated cognitive decline. Clin Trials 2004;1 440-450.
23 Kuse AR: Familial Resemblances for Cognitive Abilities from Two Test Batteries in $\mathrm{Ha}$ waii; unpublished doctoral dissertation, University of Colorado, Boulder, 1977.

24 Benton A: Differential behavioral effects in frontal lobe disease. Neuropsychologia 1968; 6:53-60.

25 Newcombe F: Missile Wound of the brain: a study of Psychological Deficits. London, Oxford University Press, 1969.

26 Benton AL: Revised Visual Retention Test. New York, Psychological Corporation, 1974.

27 Delis DC, Massman PJ, Kaplan E, McKee R, Kramer JH, Gettman D: Alternate form of the California Verbal Learning Test: development and reliability. Clin Neuropsychol 1991;5:154-162.

28 Wechsler D: Wechsler Adult Intelligence Scale - Revised. New York, Psychological Corporation, 1981.

29 Ekstrom RB, French JW, Harman HH: Manual for Kit of Factor-Referenced Cognitive Tests. Princeton, Educational Testing Service, 1976.

30 Halstead WC: Brain and Intelligence. Chicago, University of Chicago Press, 1947.

31 Basile AM, Pantoni L, Pracucci G, Asplund K, Chabriat H, Erkinjuntti T, Fazekas F, Ferro JM, Hennerici M, O’Brien J, Scheltens P, Visser MC, Wahlund LO, Waldemar G, Wallin A, Inzitari D, LADIS Study Group: Age, hypertension and lacunar stroke are the major determinants of the severity of age-related white matter changes. The LADIS Study. Cerebrovasc Dis 2006;21:315-322.

32 van Dijk EJ, Prins ND, Vrooman HA, Hoffman A, Koudstaal PJ, Breteler MMB: Progression of cerebral small vessel disease in relation to risk factors and cognitive consequences. Stroke 2008;39:2712-2719. 